\title{
Water-Soluble Polysaccharides from Ephedra alata Stems: Structural Characterization, Functional Properties, and Antioxidant Activity
}

\author{
Leila Soua ${ }^{1}$, Mohamed Koubaa ${ }^{2} \mathbb{D}$, Francisco J. Barba ${ }^{3, * \mathbb{D}}$, Jawhar Fakhfakh ${ }^{4}$, \\ Hanen Kolsi Ghamgui ${ }^{1}$ and Semia Ellouz Chaabouni ${ }^{1}$ \\ 1 Laboratory for the Improvement of Plants and Valorization of Agroresources, National School of \\ Engineering of Sfax (ENIS), University of Sfax, Sfax 3038, Tunisia; leilasoua115@gmail.com (L.S.); \\ kolsighamgui.hanen@yahoo.fr (H.K.G.); semia.chaabouni@enis.rnu.tn (S.E.C.) \\ 2 ESCOM, UTC, EA 4297 TIMR, 1 Allée du Réseau Jean-Marie Buckmaster, 60200 Compiègne, France; \\ m.koubaa@escom.fr \\ 3 Nutrition and Food Science Area, Preventive Medicine and Public Health, Food Science, Toxicology and \\ Forensic Medicine Department, Universitat de València, Faculty of Pharmacy, Avda; Vicent Andrés Estellés, \\ $\mathrm{s} / \mathrm{n}, 46100$ Burjassot, València, Spain \\ 4 Laboratory of Organic Chemistry, Natural Substances section, Faculty of Sciences of Sfax, PB 802, Sfax 3018, \\ Tunisia; jawharfakhfakh@yahoo.fr \\ * Correspondence: francisco.barba@uv.es; Tel.: +34-963-54-4972; Fax: +34-963-54-4954
}

Academic Editor: Cédric Delattre

Received: 10 April 2020; Accepted: 6 May 2020; Published: 8 May 2020

\begin{abstract}
In this study, the physicochemical characterization, functional properties, and antioxidant activity of polysaccharides extracted from Ephedra alata (EAP) were investigated. EAP were extracted in water during $3 \mathrm{~h}$ with a liquid/solid ratio of 5 in a water bath at $90{ }^{\circ} \mathrm{C}$. The structure of the extracted EAP was examined by Fourier transform infrared spectroscopy (FT-IR), scanning electron microscopy (SEM), and gas chromatography-mass spectrometry (GC-MS). The functional properties and biochemical activities of EAP were determined. The chemical analysis revealed that the contents of carbohydrates, uronic acid, and proteins were $73.24 \% \pm 1.24 \%, 6.82 \% \pm 0.57 \%$, and $6.56 \% \pm 0.36 \%$, respectively. The results showed that the extracted EAP essentially contain three functional groups: $\mathrm{C}=\mathrm{O}, \mathrm{C}-\mathrm{H}$, and $\mathrm{O}-\mathrm{H}$. SEM images showed that EAP present numerous high porosity particles. The monosaccharide composition revealed a polymer composed of glucose $(43.1 \%)$, galactose $(36.4 \%)$, mannose $(14.9 \%)$, arabinose $(3.7 \%)$, and gluconic acid (1.7\%). EAP showed interesting functional properties (solubility, oil holding capacity, foaming and emulsion properties). Finally, the results revealed that EAP displayed excellent antihypertensive and antioxidant activities. Overall, EAP present a promising natural source of food additives, antioxidants, and antihypertensive agents.
\end{abstract}

Keywords: Ephedra alata; polysaccharides; physicochemical characterization; functional properties; antioxidant activities

\section{Introduction}

Polysaccharides are carbohydrate polymers that are widely present in plants, animals, and microorganisms [1]. They have drawn considerable attention owing to their widespread use in different industrial fields such as foods and pharmaceuticals [2]. Many research works have focused on their functional properties (e.g., water holding capacity, oil holding capacity) [3] and biological activities (e.g., anticancer, antioxidant, antitumor, immunomodulatory, etc.) [4,5]. It has been demonstrated that the functional properties of polysaccharides are firmly dependent on their basic structure, which 
includes their molecular weight, monosaccharides composition, and the configuration of the glycosidic bonds $[6,7]$.

Ephedra alata, commonly known in Tunisia as "alenda", belongs to the Ephedraceae family containing more than 60 species of nonflowering seed plants, with light green densely branched dioecious small and perennial stiff shrub about $50-100 \mathrm{~cm}$ tall [8]. This species is mainly distributed in arid environments, often near shifting sand dunes of Iran, Algeria, Iraq, Chad, Egypt, Palestine, Lebanon, Jordan, Saudi Arabia, Morocco, Syria, Libya, Mauritania, Mali, Somalia, and Tunisia, where it grows wildly on the gravely rocky, sandy, and clay soil [8]. The decoction of E. alata stem is used in folk medicine as a potential stimulant, to treat different disorders (e.g., kidney, bronchi, circular system, digestive system disorders), to relieve asthma attack, and as antifungal [9]. The plant stems are usually chewed to treat bacterial and fungal infections [10].

The review of the literature shows that most of the studies of $E$. alata were focused on its content in alkaloids and phenolic compounds. Nonetheless, in other species of Ephedra, such as E. sinica, the extracted polysaccharides have proven to possess biological activities [11]. For instance, it has been demonstrated that they could be used to alleviate the airway and pulmonary inflammation and could become a new therapeutic drug for the treatment of chronic obstructive pulmonary diseases (COPD) [11]. Acidic polysaccharides extracted from E. sinica were found to possess immunosuppressive activity and it was demonstrated that the main acidic polysaccharide, ESP-B4, had potential therapeutic effects on rheumatoid arthritis. ESP-B4 reduces the release of inflammatory factors and cytokines by inhibiting the toll like receptor 4 (TLR4) signaling pathway [12]. In addition, it was found that, in the Ephedra root extracts, ephedrannin A (72) and ephedrannin B (73) had anti-inflammatory effects. They could suppress the transcription of the tumor necrosis factor (TNF- $\alpha$ ) and Interleukin (IL-1 $\beta$ ) and inhibit the lipopolysaccharide-induced inflammation [13]. In another study, it was found that the methanolic extracts of E. major aerial parts and roots inhibited the fungal growth and the production of aflatoxin B1 (AFB1), dose-dependently [14]. Moreover, the essential oil extracts from the aerial parts of this plant significantly inhibited the fungal growth at the highest concentration of $1000 \mu \mathrm{g} \cdot \mathrm{mL}^{-1}$ without any obvious effect on AFB1 production at all concentrations tested $\left(0-1000 \mu \mathrm{g} \cdot \mathrm{mL}^{-1}\right)$ [14].

Angiotensin-converting enzyme (ACE) is a dipeptidyl carboxypeptidase (EC 3.4.15.1) and is widely distributed in mammalian tissues [15]. It converts angiotensin I to angiotensin II, a vasoconstrictor. It also inactivates bradykinin, which is a vasodilator peptide. This enzyme plays an important role in the regulation of blood pressure through these two mechanisms [16]. ACE inhibitors are effective antihypertensive agents. It is thus interesting to investigate how ACE improves the body's antioxidant capacity for health benefits. Furthermore, in the conditions of hypertension, angiotensin II amplifies the oxidative stress as it disturbs many of its cellular functions through stimulating the formation of intracellular reactive radical species (ROS) [17]. Therefore, in addition to blood pressure control, ACE inhibitors have been shown to intensify the antioxidant defense system in animals and humans by inhibiting the formation of angiotensin II [18].

Besides, studies on the antioxidant potential of polysaccharides isolated from plant species have increased remarkably owing to their strong efficiency [19]. Moreover, as most of the synthetic antioxidants are potentially harmful to humans, it is particularly important to seek natural antioxidants instead. In fact, most of the polysaccharides extracted from natural resources present low toxicity and exhibit a strong biological activity when compared with other natural antioxidants [20]. It should be noted that many plant-based products rich in polysaccharides, such as that from Astragalus membranaceus, exist in the market and are commercialized for their health-related properties.

Owing to the above-mentioned beneficial properties of polysaccharides, and especially those extracted from Ephedra species, the current work aims to extract water-soluble polysaccharides from E. alata (EAP) stems, and then to study their antioxidant activity, functional properties, as well as physicochemical characterization. 


\section{Results and Discussion}

\subsection{EAP Content and Chemical Composition}

The recovered EAP content was $4 \% \pm 1.02 \%$, which is higher than that obtained from E. sinica stems (0.85\%) [21], and in the same range as that extracted from E. sinica Stapf stems (4.9\%) [22]. Such variability in the extraction yields could be related to several factors such as environmental conditions, habitat, physiological factors, growth cycle, and seasonal variations [23]. The harvesting period could be a major factor responsible for the low extraction yield. Besides, it was reported that the extraction yield of polysaccharides is highly influenced by the extraction time and temperature, as well as the solid/liquid ratio [24]. The chemical composition of the extracted EAP on a dry weight basis (Table 1) shows that the carbohydrates present the most important part $(73.24 \% \pm 1.94 \%)$. This value was higher than that reported for water-soluble polysaccharides extracted from Carex meyeriana Kunth, which was about $38.28 \%$ [25]. Moreover, the uronic acid content was about $6.82 \% \pm 0.57 \%$, which was higher than that found in the polysaccharides extracted from C. meyeriana Kunth $(4.76 \% \pm 0.48 \%)$ [25]. Low protein content $(6.56 \%)$ was present in the extracted EAP, which was similar to that reported by Hu et al. [25] for polysaccharides extracted by hot water from C. meyeriana Kunth $(6.38 \% \pm 0.28 \%)$. It should be noted that the extraction yield of polysaccharides is highly influenced by the extraction time and temperature, as well as the solid/liquid ratio [24].

Table 1. Characterization of the extracted polysaccharides from Ephedra alata (EAP).

\begin{tabular}{cc}
\hline Compound & Content $^{*}$ \\
\hline Ash & $10.24 \pm 0.24$ \\
Carbohydrates & $73.24 \pm 1.94$ \\
Proteins & $5.68 \pm 0.01$ \\
Lipids & $1.09 \pm 0.31$ \\
Uronic acid & $6.82 \pm 0.57$ \\
Moisture & $2.78 \pm 0.3$
\end{tabular}

* Ash, carbohydrates, proteins, lipids, and uronic acid are expressed in \% dry weight (g/100 g dry material). Moisture content is expressed in $\%$ fresh material $(\mathrm{g} / 100 \mathrm{~g}$ fresh material).

The ash content of EAP was about $10.24 \% \pm 0.24 \%$, which was higher than some commercially available polysaccharides, such as agar and carrageenan, ranging from $2.5 \% \pm 0.03 \%$ to $2.7 \% \pm 0.031 \%$ [26]. Regarding the mineral composition of EAP extract, the results presented in Table 2 show that sodium was the most abundant mineral $(223.2 \mathrm{mg} / 100 \mathrm{~g})$, followed by calcium (197.85 mg/100 g), and then potassium (108.5 mg/100 g). As reported by Jayasinghe et al. [26], the commercial agar contains a similar amount of $\mathrm{Mg}$ and $\mathrm{K}$, whereas EAP present high levels of $\mathrm{Na}$ and Ca.

Table 2. Mineral composition of EAP expressed in $\mathrm{mg} / 100 \mathrm{~g}$ of dry matter.

\begin{tabular}{lc}
\hline Mineral & $\mathbf{m g} / \mathbf{1 0 0} \mathbf{g}$ of Dry Matter \\
\hline $\mathrm{Ca}$ & $197.85 \pm 7.24$ \\
$\mathrm{Na}$ & $223.2 \pm 11.02$ \\
$\mathrm{~K}$ & $108.5 \pm 4.10$ \\
$\mathrm{Zn}$ & $0.140 \pm 0.11$ \\
$\mathrm{Mg}$ & $63.39 \pm 12.25$ \\
$\mathrm{Mn}$ & $0.563 \pm 0.08$ \\
$\mathrm{Fe}$ & $0.067 \pm 0.12$ \\
$\mathrm{Cu}$ & $<0.001$ \\
\hline
\end{tabular}


The measurement of Aw shows that the EPA present an Aw of $0.37 \pm 0.006$, which is situated according to the map of stability in an area where the oxidation of lipids is low, non-enzymatic browning (Maillard reaction) is slow, and the enzyme activities are required to prevent the development of microorganisms. When polysaccharides are used in food formulations, they should not give any off-flavor or produce any side effects in the final products. Moreover, the EAP showed a high light value $\left(L^{*}=70.09 \pm 0.08\right)$. The $a^{*}$ and $b^{*}$ values recorded were $6.05 \pm 0.01$ and $20.23 \pm 0.03$, respectively (Table 1). These results concur with previous ones reported by Ben Jeddou et al. [27], showing that the polysaccharides extracted from potato peels displayed light color and a slight degree of redness.

\subsection{UV/Visible Spectroscopy}

The maximum absorption peaks of EAP found in the UV/visible spectrum ranged from 200 to $240 \mathrm{~nm}$ (Figure 1A). On the basis of their absorption maxima between 204 and $216 \mathrm{~nm}$ and the absence of any absorption in the range of $260-280 \mathrm{~nm}$, EAP was identified as polysaccharides and not proteins or nucleic acids [2].

A.

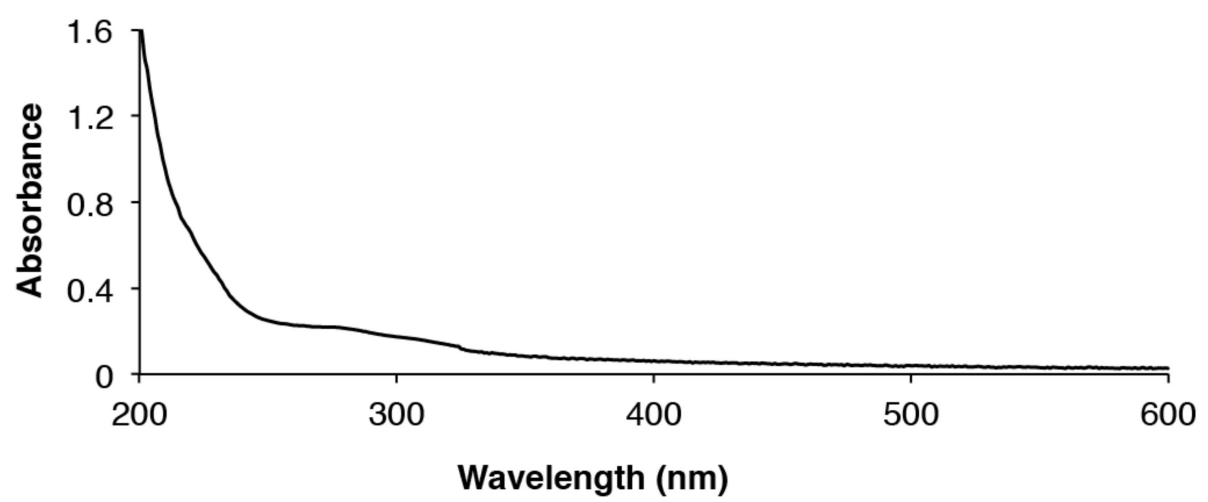

B.

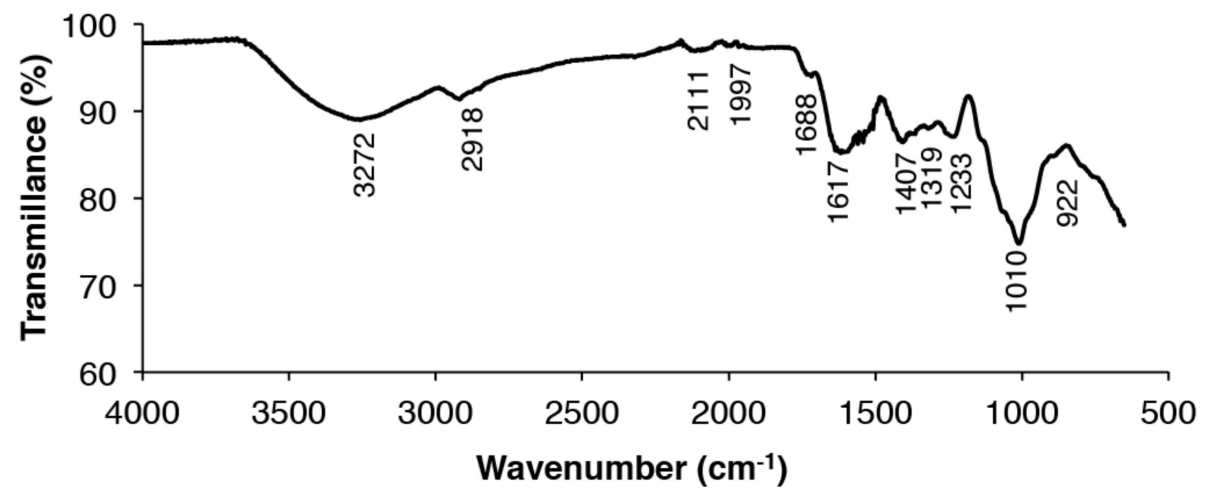

Figure 1. (A) UV absorption spectrum of Ephedra alata (EAP). (B) Fourier transform infrared (FT-IR) spectrum of EAP.

\subsection{Monosaccharide Composition}

The monosaccharide composition of EAP determined by gas chromatography-mass spectrometry (GC-MS) revealed the presence of different carbohydrate moieties in varied proportions (Table 3). Acid hydrolysis of EAP showed that glucose was the most abundant sugar $(43.1 \%)$, followed by galactose $(36.4 \%)$, mannose $(14.9 \%)$, arabinose $(3.7 \%)$, and gluconic acid $(1.7 \%)$. 
Table 3. Monosaccharide composition of EAP determined by gas chromatography-mass spectrometry (GC-MS).

\begin{tabular}{lc}
\hline Monosaccharide & Peak Area \% \\
\hline Galactose & $36.4 \pm 0.24$ \\
Arabinose & $3.7 \pm 1.02$ \\
Glucose & $43.1 \pm 1.10$ \\
Mannose & $14.9 \pm 0.11$ \\
Gluconic acid & $1.7 \pm 1.25$ \\
\hline
\end{tabular}

\subsection{Fourier Transform Infrared (FT-IR) Spectroscopy Analysis of EAP}

FT-IR spectroscopy was performed in the region ranging from 4000 to $400 \mathrm{~cm}^{-1}$ to further characterize the EAP. As presented in Figure 1B, EAP displayed typical peaks of polysaccharides at $3272,2918,1617,1407,1233,1010$, and $922 \mathrm{~cm}^{-1}$. The peak observed at $3272 \mathrm{~cm}^{-1}$ corresponds to the stretching vibration of $\mathrm{OH}$ groups owing to inter- and intra-molecular hydrogen bands [28]. The peak observed at $2918 \mathrm{~cm}^{-1}$ represents the stretching of $\mathrm{CH}$ groups of the free sugars [29]. Furthermore, the peaks at $1617 \mathrm{~cm}^{-1}$ and $1688 \mathrm{~cm}^{-1}$ were attributed to carbonyl ester $(C=O)$ groups [30], whereas the region between $1617 \mathrm{~cm}^{-1}$ and $1688 \mathrm{~cm}^{-1}$ reflects the bound water [31]. Finally, the region between $922 \mathrm{~cm}^{-1}$ and $1010 \mathrm{~cm}^{-1}$ is attributed to the presence of carbohydrate fingerprints for the functional groups characterizing polysaccharides as bending $(\mathrm{O}-\mathrm{H})$, stretching $(\mathrm{C}-\mathrm{O}-\mathrm{C})$, and deforming $\left(\mathrm{CH}_{3}\right)$ vibrations. The peaks below $1000 \mathrm{~cm}^{-1}$ also indicate the presence of visible bands and/or the possible linkages between two monosaccharide molecules [24].

\subsection{Scanning Electron Microscopy (SEM)}

The shape and surface characteristics of the EAP were investigated using SEM analysis and the obtained images are presented in Figure 2A,B. The results showed that the EAP present numerous large size and high-porosity particles. These results were different from those obtained by Cheng et al. [32], in which it was reported that E. acuminatum polysaccharides had a flat and smooth surface.
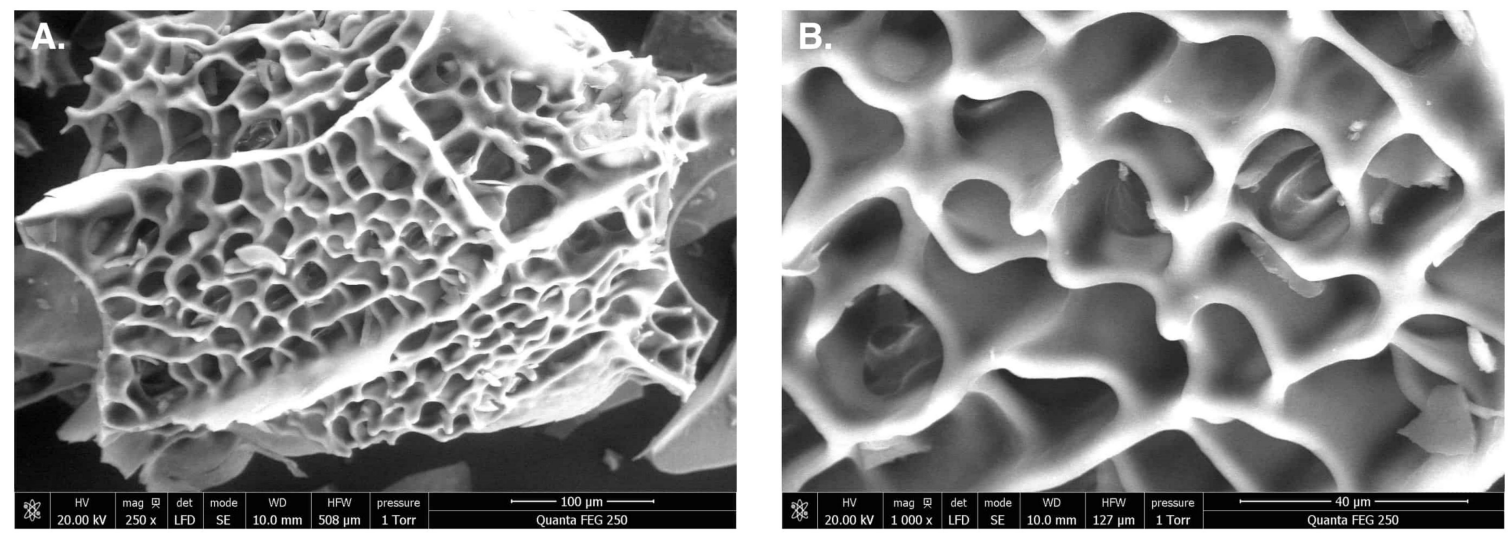

Figure 2. Scanning electron microscopy images of EAP. (A). Image magnified 250 times; (B). Image magnified 1000 times.

\subsection{Functional Properties}

\subsubsection{Water-Holding (WHCs) and Fat-Binding Capacities (FBCs)}

WHC and FBC are functional properties in food processing that are closely related to texture via the interaction between the components, including water and oil. The results show that EAP have a WHC of $2 \pm 0.10 \mathrm{~g} \mathrm{H}_{2} \mathrm{O} / \mathrm{g}$ sample, which is higher than commercial citrus pectin $(1.38 \pm 0.06 \mathrm{~g}$ $\mathrm{H}_{2} \mathrm{O} / \mathrm{g}$ sample), Arabic gum $(0.28 \pm 0.15)$, and wheat starch $(0.74 \pm 0.02)$, previously reported by 
Gannasin et al. [33]. The FBC exhibited by EAP ( $4 \pm 0.1 \mathrm{~g}$ oil $/ \mathrm{g}$ sample) was also higher than that displayed by commercial citrus pectin $(1.55 \pm 0.09 \mathrm{~g}$ oil $/ \mathrm{g}$ sample), Arabic gum $(1.00 \pm 0.10 \mathrm{~g}$ oil $/ \mathrm{g}$ sample), and wheat starch $(0.92 \pm 0.03 \mathrm{~g}$ oil $/ \mathrm{g}$ sample). This difference is probably linked to the porosity of EAP structure rather than the affinity of the polysaccharide to oil [34].

\subsubsection{Foaming Properties}

Foam development and stability largely depend on the interfacial properties of the surface-active components used in the formulation [35]. Foam capacity (FC) and foam stability (FS) of EAP were assessed at different concentrations $(0.5 \%, 1 \%, 2 \%, 3 \%, 4 \%$, and $5 \% w / v)$. The results obtained (Figure 3A) show a high FC of EAP at $2 \%$ and $3 \%$ concentrations. In contrast, the FC decreased slightly from $95 \% \pm 2.78 \%$ to $85 \% \pm 1.41 \%$ at a concentration of $4 \%$. The foaming capacity of EAP was better than some commercial hydrocolloids such as bovine gelatin (61.92\%) and Arabic gum (25\%) [33]. Moreover, carrageenan, wheat starch, and xanthan gum have no FC [33]. On the other hand, the foam made in the presence of $2 \%$ EAP was stable and decreased slightly after $60 \mathrm{~min}$ (Figure 3B). These interesting FC and FS values of the EAP suggest their capacity to increase the viscosity of various food formulations and forming a system stabilizing the interfacial gas-liquid film [36].

A.

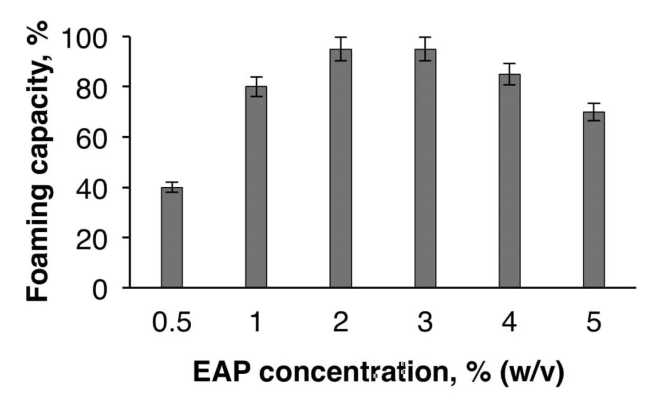

C.

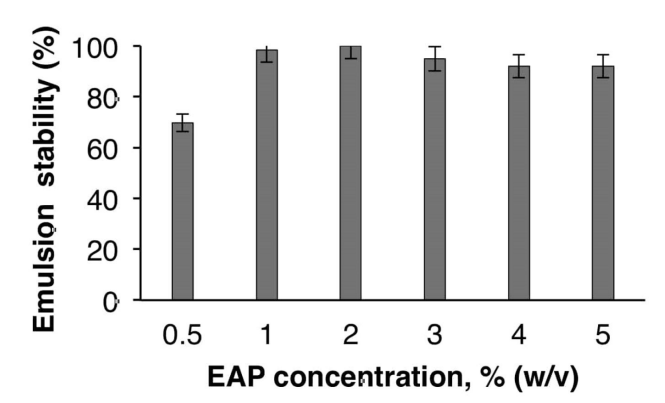

B.

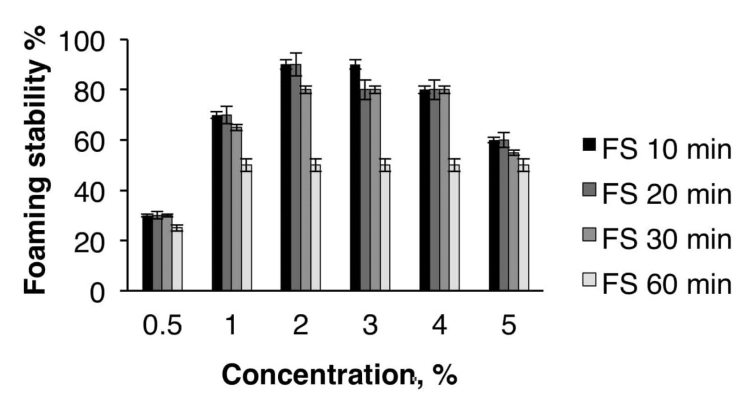

D.

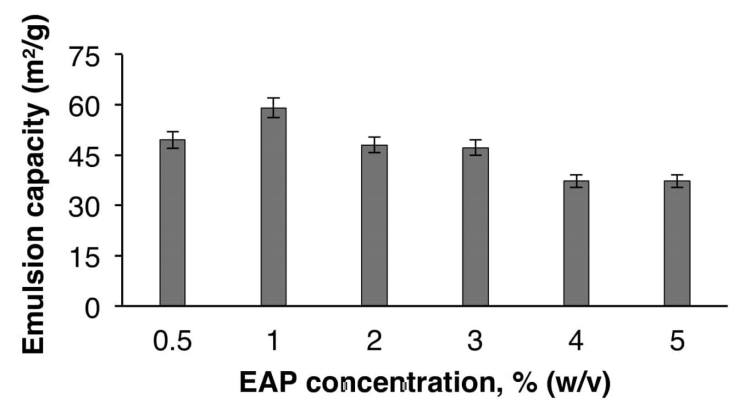

Figure 3. (A) Foam capacity of EAP. (B) Foam stability (FS) of EAP. (C) Emulsion stability of EAP. (D) Emulsion capacity of EAP.

\subsubsection{Emulsion Capacity (EC)}

An emulsion is an intimate mixture of two or more liquids that are generally immiscible. The study of the EC and emulsion stability (ES) of EAP at various concentrations $(0.5 \%-5 \% w / v)$ (Figure 3C,D) shows that the highest EC value was obtained at a concentration of $1 \%$. From a concentration of $3 \%$, the EC started to decrease gradually until $37.18 \mathrm{~m}^{2} / \mathrm{g}$ at $5 \%$. Concerning the ES, the formed emulsions were stable at a concentration of $2 \%$ and then decreased below this concentration, which was equal to $92 \%$ at a concentration of 5\%. A similar trend was observed by Benhura et al. [37], who evaluated the ES of Arabic gum at concentrations ranging from $0.25 \%$ to $1 \%$. The obtained results in the current 
work show that the efficiency of EAP depends on the concentration of this polymer in the aqueous phase of the emulsion.

\subsection{Antioxidant Activities of EAP}

\subsubsection{Determination of Total Antioxidant Capacity (TAC)}

The phosphomolybdate method is based on the reduction of $\mathrm{Mo}(\mathrm{VI})$ to $\mathrm{Mo}(\mathrm{V})$ at acidic $\mathrm{pH}$ and the formation of a green molybdate phosphate complex in the presence of an antioxidant molecule. The results presented in Figure 4A indicate that the TAC was proportional to the concentration of EAP. The half maximal inhibitory concentration $\left(\mathrm{IC}_{50}\right)$ of EAP was estimated to be $3.2 \mathrm{mg} / \mathrm{mL}$. This value was higher than that obtained for butylated-hydroxyanisole (BHA) $\left(\mathrm{IC}_{50}=0.4 \mathrm{mg} / \mathrm{mL}\right.$ ) used as the positive control. Despite the lower antioxidant activity compared with that of BHA, the obtained results indicated that EAP present an interesting natural antioxidant extract [26].

A.

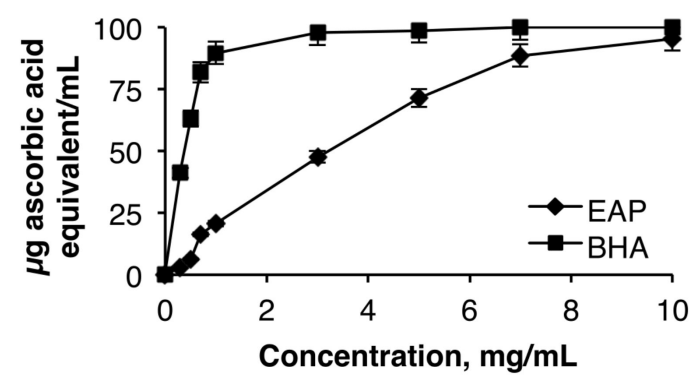

C.

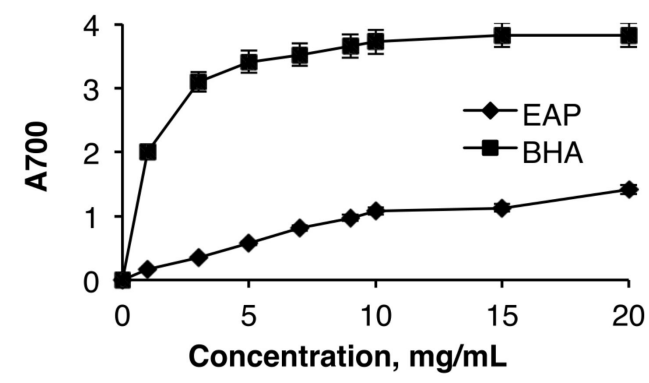

E.

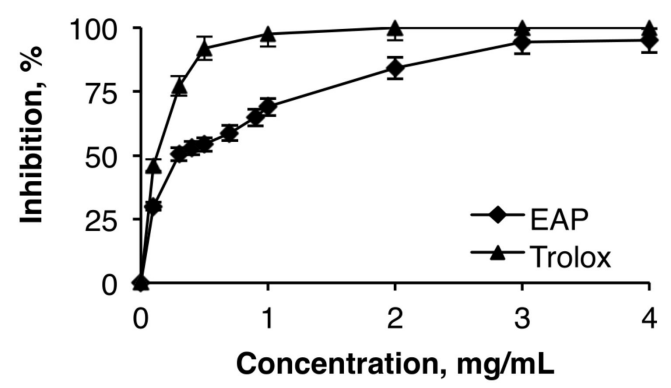

B.

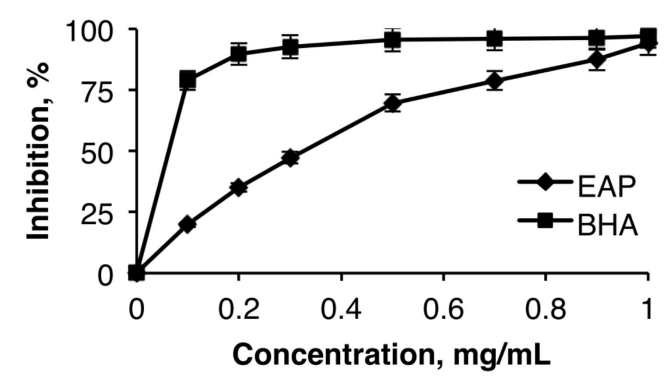

D.

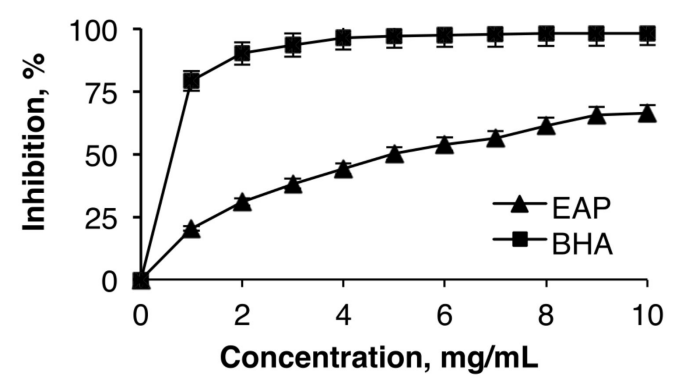

F.

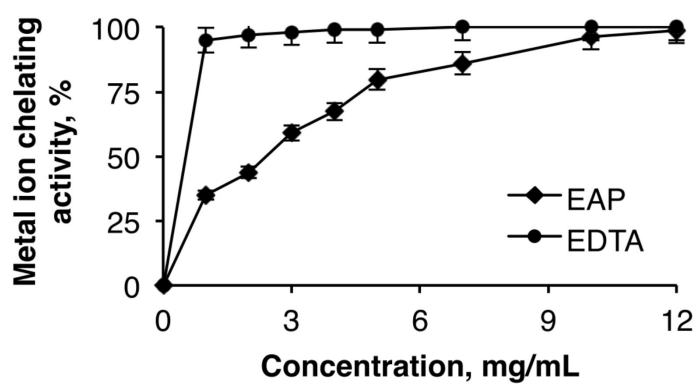

Figure 4. (A) Total antioxidant capacity of EAP. (B) DPPH (2,2-diphenyl-1-picrylhydrazyl) free radical scavenging activity of EAP. (C) Reducing power capacity of EAP. (D) $\beta$-Carotene bleaching activity of EAP. (E) ABTS (2,2'-azino-bis(3-ethylbenzothiazoline-6-sulfonic acid) free radical-scavenging activity of EAP. (F) Ferrous ion-chelating activity of EAP. BHA, butylated-hydroxyanisole. 


\subsubsection{DPPH Free Radical Scavenging Activity}

As a stable free radical, DPPH has been widely used to evaluate the free radical scavenging capacity of natural compounds by donating hydrogen to form a stable DPPH molecule [38]. The free radical scavenging activity of EAP was determined and compared to the reference antioxidant BHA. Figure 4B describes the DPPH scavenging ability of EAP, and shows an obvious antioxidant activity in a concentration-dependent manner. For all concentrations, EAP showed a dose-dependent DPPH radical scavenging activity, with an effective scavenger at lower concentrations $(0.2-0.3 \mathrm{mg} / \mathrm{mL})$. At $0.3 \mathrm{mg} / \mathrm{mL}$, the DPPH scavenging activity of EAP was $47.32 \% \pm 0.32 \%$, which was slightly lower than the polysaccharide fraction reported by Chen et al. [39] (55.74\% $\pm 4.02 \%)$. At a higher concentration range $(0.5$ to $1 \mathrm{mg} / \mathrm{mL})$, the DPPH scavenging activities of EAP increased proportionally to the concentrations. The interesting EAP radical scavenging activity was probably owing to the presence of hydroxyl and carboxyl groups of uronic acids in the polysaccharides, which act as a hydrogen donor to scavenge the DPPH free radicals and, consequently, neutralize the effect of oxidative stress.

\subsubsection{Reducing Power Capacity}

The reducing power capacity of EAP to convert $\mathrm{Fe}^{3+}$ to $\mathrm{Fe}^{2+}$ was followed by measuring the absorbance at $700 \mathrm{~nm}$, corresponding to the formation of Perl's Prussian blue at $700 \mathrm{~nm}$. The results in Figure $4 \mathrm{C}$ show that the ferric reducing power increased proportionally to the concentrations of EAP within the range of $1-20 \mathrm{mg} / \mathrm{mL}$. However, compared with BHA, EAP exhibited a relatively lower activity. It has been reported that the reducing power of plant polysaccharides was often associated with the capacity of reacting with given precursors of peroxide [40].

\subsection{4. $\beta$-Carotene Bleaching Assay}

The $\beta$-carotene bleaching test simulates the oxidation of membrane lipids. It is thus considered a good model for membrane-based lipid peroxidation. The oxidation of linoleic acid during this assay generates peroxyl free radicals, which can oxidize the unsaturated $\beta$-carotene. The presence of an antioxidant molecule in the medium will minimize this oxidation. The antioxidant activity of EAP was assessed using the $\beta$-carotene/linoleic acid bleaching assay. As shown in Figure $4 \mathrm{D}$, the trend of concentration dependence was clear. Considering the $\mathrm{IC}_{50}$ values, $\mathrm{EAP}\left(\mathrm{IC}_{50}=4.2 \mathrm{mg} / \mathrm{mL}\right)$ was found to be more efficient compared with the water-soluble polysaccharides extracted from almond by-product $\left(\mathrm{IC}_{50}=4.46 \mathrm{mg} / \mathrm{mL}\right)$, but was lower than that of pistachio by-product $\left(\mathrm{IC}_{50}=3.39 \mathrm{mg} / \mathrm{mL}\right)$ [41]. The $\mathrm{IC}_{50}$ value recorded for EAP was higher than that of $\mathrm{BHA}$, which was in the range of $0.6 \mathrm{mg} / \mathrm{mL}$.

\subsubsection{ABTS Free Radical-Scavenging Ability}

The potential of EAP to scavenge free radicals was also assessed by their ability to quench $\mathrm{ABTS}^{\bullet+}$. The results presented in Figure 4E show that the EAP exhibit a strong radical scavenging activity on ABTS at a concentration of $2 \mathrm{mg} / \mathrm{mL}$ and the removal of ABTS radical reached $84.17 \% \pm 2.16 \%$. At the same concentration, this value was higher than that reported by Hammami et al. [42] (72.32\%). For instance, the scavenging effects of ABTS radicals on polysaccharides were relatively lower than that of Trolox at the same concentration. The kinetics of the antioxidant activity of the ABTS radical can be influenced by the chemical structure, the molecular weight, and the high sulfate level [42].

\subsubsection{Ferrous Ion-Chelating Activity}

Chelating agents may inhibit lipid oxidation through disrupting the formation of $\mathrm{Fe}^{2+}$-ferrozine complex. In the current study, EAP exhibited an excellent chelating activity, which increased in a dose-dependent manner and reached $96.23 \%$ at the dose of $10 \mathrm{mg} / \mathrm{mg}$. However, this activity was lower than that of ethylenediaminetetraacetic acid (EDTA) at all tested concentrations (Figure 4F). This chelating activity was much higher than that of laminaran purified from Cystoseira barbata seaweed, which was $78 \%$ at a concentration of $20 \mathrm{mg} / \mathrm{mL}$ [43]. The $\mathrm{IC}_{50}$ of $\mathrm{Fe}^{2+}$ ion chelating ability of EAP was 
equal to $2.4 \mathrm{mg} / \mathrm{mL}$. These findings indicated that EAP can exhibit antioxidant activity by capturing iron ions. Song et al. [44] pointed out that the presence of carboxyl groups in galacturonic acid units significantly increases their chelating potentialities.

\subsection{ACE Inhibitory Activity of EAP}

The inhibition of angiotensin I-converting enzyme (ACE) by dietary anti-hypertensive agents is a promising strategy for hypertension management. In fact, recent research showed that ACE inhibition might be a useful therapy for the treatment of high blood pressure. As synthetic ACE inhibitors may cause adverse side effects, plant molecules may offer natural and cost-effective alternative ACE inhibitors for the treatment and prevention of hypertension. The results presented in Figure 5 show that EAP exhibit ACE-inhibitory activity. This activity increased in a concentration-dependent manner. The ACE inhibitory effect of EAP $(82.49 \% \pm 0.66 \%$ at $1 \mathrm{mg} / \mathrm{mL})$ was lower than that $\mathrm{M}$. charantia bioactive polysaccharide (94.1\%) [45], but higher than that of polysaccharides extracted from almond by-product $(79.5 \% \pm 2.8 \%$ at $5 \mathrm{mg} / \mathrm{mL})$ and pistachio by-product $(81.78 \% \pm 1.1 \%$ at $5 \mathrm{mg} / \mathrm{mL})[41]$. The $\mathrm{IC}_{50}$ value of EAP was also determined $\left(\mathrm{IC}_{50}=0.21 \mathrm{mg} / \mathrm{mL}\right)$. It was equal to that of watermelon rinds $\left(\mathrm{IC}_{50}=0.21 \mathrm{mg} / \mathrm{mL}\right)$, but ten times lower than that of polysaccharides derived from almonds $\left(\mathrm{IC}_{50}=\right.$ $2.81 \mathrm{mg} / \mathrm{mL})$ and pistachios $\left(\mathrm{IC}_{50}=2.59 \mathrm{mg} / \mathrm{mL}\right)$ [41]. Although the ACE inhibitory mechanism of polysaccharides remains unknown, the inhibitory activity of EAP was presumed to be the result of the presence of galacturonic acid, which could be ionized when EAP was dissolved in water, and then the release of hydrogen ions. This process created an acidic environment, which was not suitable for ACE because its optimum $\mathrm{pH}$ is 8.3. Under acidic conditions, ACE would be denatured and thus lose its activity [22].

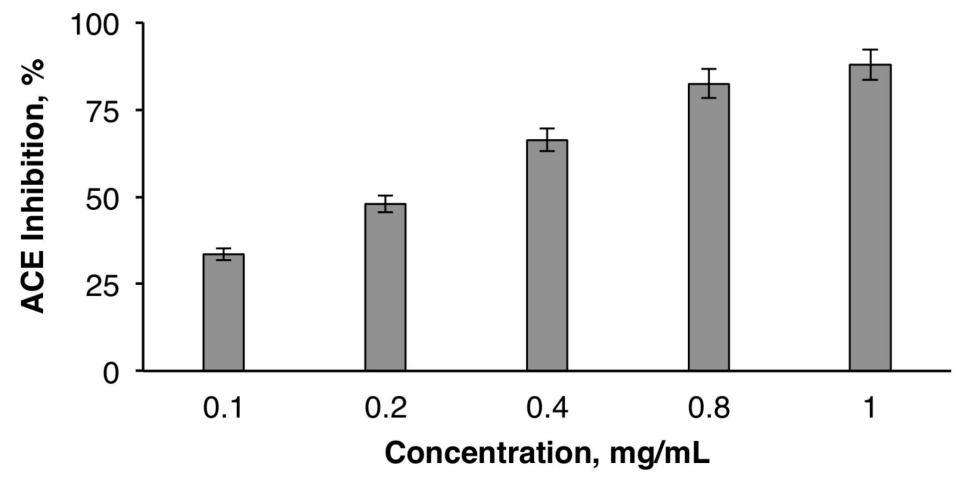

Figure 5. Angiotensin I-converting enzyme (ACE) inhibitory activity of EAP.

\section{Materials and Methods}

\subsection{Plant Material}

The stems of E. alata were collected in December 2017 from the region of Chebba (Mahdia city, Tunisia) (Figure 6A). The aerial parts were first washed with distilled water, dried at $50{ }^{\circ} \mathrm{C}$ in the oven for $48 \mathrm{~h}$, and then ground to a fine powder in a mixer grinder (Moulinex, Fontenay-sous bois, France). The obtained powder was then stored at $4{ }^{\circ} \mathrm{C}$ until use. 
A.

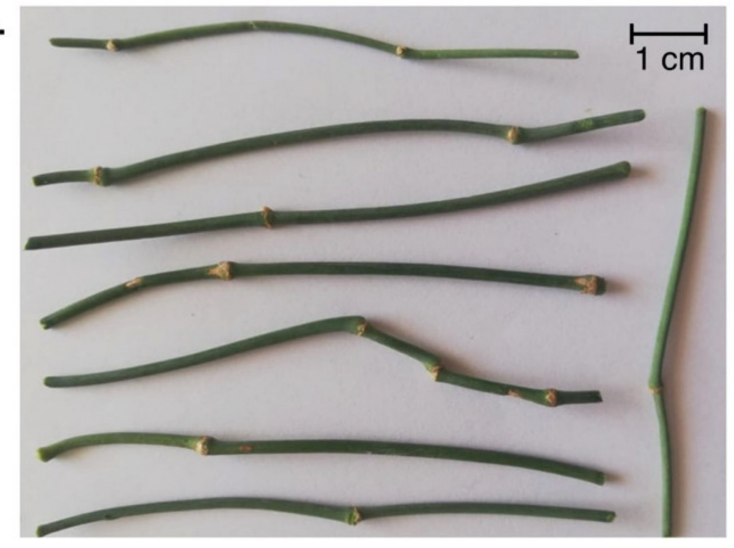

B.
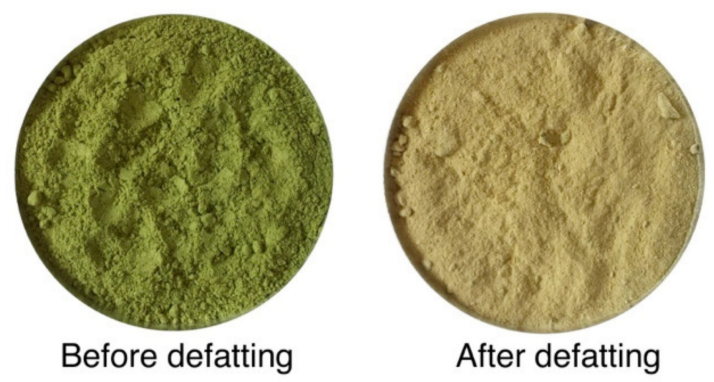

Figure 6. (A) Photo of E. alata stems. (B) E. alata powder aspects before and after defatting.

\subsection{Reagents}

The chemicals obtained from Sigma Chemical Co. (St. Louis, MO, USA) were DPPH (2,2-diphenyl1-picrylhydrazyl), angiotensin I-converting enzyme from rabbit lung, ACE synthetic substrate hippuryl-1-histidyl-1-leucine (HHL), butylated-hydroxyanisole (BHA), $\beta$-carotene, ascorbic acid, linoleic acid, and Tween 40. All the other chemicals, namely trichloro-acetic-acid (TCA), potassium ferricyanide, sodium hydroxide, and ferric chloride, were of analytical grade.

\subsection{Extraction of Water-Soluble Polysaccharide}

Water-soluble polysaccharides from E. alata stems (EAP) were extracted as previously described [12], with modifications. Dried aerial parts of E. alata were defatted with $95 \%$ ethanol solution for $2 \mathrm{~h}$ to eliminate small lipophilic molecules and impurities (Figure 6B). The defatted residue was mixed with distilled water for $3 \mathrm{~h}$ with a liquid/solid ratio of 5 in a water bath at $90^{\circ} \mathrm{C}$. The extraction step was performed twice to ensure the maximum yield of polysaccharides. The filtrates obtained were combined and concentrated 20 -fold using a rotary evaporator maintained at $50{ }^{\circ} \mathrm{C}$ under vacuum. The extracted EAP were then precipitated by adding three volumes of absolute ethanol and incubation overnight at $4{ }^{\circ} \mathrm{C}$. After centrifugation for $15 \mathrm{~min}$ at $5869 \times \mathrm{g}$, the pellet was solubilized in distilled water. The solution was dialyzed against deionized water to remove the inorganic salts, and then freeze-dried to obtain lyophilized polysaccharides. The extraction yield expressed in $\%$ was calculated as the ratio of the crude dried polysaccharides' weight divided by that of the initial raw material and multiplied by 100 .

\subsection{Physicochemical Characterization of EAP}

The total carbohydrate content of EAP was measured by the phenol-sulfuric acid method using glucose as standard [46]. Uronic acid was estimated by the carbazole method using glucuronic acid as standard for the calibration [47]. The total crude protein content of the samples was determined by Kjeldahl' s method $(\mathrm{N} \times 6.25)$ [48]. The moisture, ash, and lipid contents of EAP were analyzed according to the American Association of Cereal Chemists 2000 standard methods. 


\subsection{Monosaccharide Composition of EAP}

The monosaccharide composition of the extracted EAP was performed by gas chromatographymass spectrometry (GC-MS) after hydrolysis for $2 \mathrm{~h}$ with a trifluoroacetic acid (TFA) solution (2 M) at $120{ }^{\circ} \mathrm{C}$. A sample of $50 \mathrm{mg}$ lyophilized hydrolysate was silylated by a mixture of pyridinehexamethyldisilazane-trimethylchlosilane, 9:3:1 $(v / v / v)$. Analysis of the obtained derivatives from the trimethylsilyl sugars was carried out by a Varian 3800 chromatograph using a fused silica capillary column $(30 \mathrm{~m} \times 0.25 \mathrm{~mm})$ coated with DB-225ms (Agilent Technologies, Les Ulis, France). The separation and elution conditions were as follows: the injected volume was $1 \mu \mathrm{L}$ and the temperatures of the detector and the injector were both set at $320^{\circ} \mathrm{C}$. The temperature of the column was set at $100{ }^{\circ} \mathrm{C}$ for $1 \mathrm{~min}$ and then ramped from 100 to $260^{\circ} \mathrm{C}$ at $4{ }^{\circ} \mathrm{C} / \mathrm{min}$, and held for $10 \mathrm{~min}$ at $260^{\circ} \mathrm{C}$. The carrier gas used was helium at a flow of $1 \mathrm{~mL} / \mathrm{min}$.

\subsection{Water Activity of EAP}

Water activity $\left(\mathrm{A}_{\mathrm{w}}\right)$ was measured using the apparatus $\mathrm{A}_{\mathrm{w}}$ SPRINT TH-500 (Novasina, Lachen, Switzerland). The measurement consisted of filling a plastic capsule with EAP, followed by reading the $\mathrm{A}_{\mathrm{w}}$ at $25^{\circ} \mathrm{C}$.

\subsection{Color Determination of EAP}

Color parameters of EAP powder were measured with a portable colorimeter Chroma Meter CR-410 (Konica Minolta Sensing, Osaka, Japan) based on $\mathrm{L}^{*}, \mathrm{a}^{*}$, and $\mathrm{b}^{*}$ values. After calibration, the sample was placed on a holding device. $\mathrm{L}^{*}$ value indicates the lightness, $\mathrm{a}^{*}$ value gives the degree of the red-green color, and $b^{*}$ value indicates the degree of the yellow-blue color [49].

\subsection{UV Absorption Spectrum of EAP}

EAP was dissolved in distilled water to get a final concentration of $1 \mathrm{mg} / \mathrm{mL}$, and analyzed for full band scanning in the range of 200-600 nm [27], using a UV spectrometer Helios Omega UV-Vis (Thermo Fisher Scientific, Villebon-sur-Yvette, France).

\subsection{Infrared Spectroscopic Analysis of EAP}

The Fourier transform infrared (FT-IR) spectrum of EAP was obtained using an FT-IR spectrophotometer Spectrum BX FT-IR (PerkinElmer, Villebon-sur-Yvette, France). The ground sample was incorporated into spectroscopic grade potassium bromide $(\mathrm{KBr})$ powder and then pressed into a $1 \mathrm{~mm}$ disk. The results were recorded in the wavenumber range of $4000-400 \mathrm{~cm}^{-1}$.

\subsection{Scanning Electron Microscopy of EAP}

The EAP were first coated with gold using a sputter coater JFC-1100 (JEOL Ltd., Tokyo, Japan), and then examined by a scanning electron microscope JSM-5400 (JEOL Ltd., Tokyo, Japan) under vacuum conditions.

\subsection{Functional Properties of EAP}

\subsubsection{Water-Holding Capacity}

The water-holding capacity (WHC) of the EAP was determined according to the method developed by Lin et al. [50] and improved by Bayar et al. [51]. A sample of $500 \mathrm{mg}$ of the extracted EAP was placed in a centrifuge tube and weighed (tube with polysaccharide). Then, $50 \mathrm{~mL}$ of distilled water was added, and the suspension was held at room temperature for $1 \mathrm{~h}$ with vortexing for $5 \mathrm{~s}$ every $15 \mathrm{~min}$. After 20 min centrifugation at 5000 $\mathrm{g}$ using a refrigerated centrifuge Rotina 380R (Hettich-Heinze $\mathrm{GmbH} \& \mathrm{Co} . \mathrm{KG}$, Spenge, Germany), the upper phase was eliminated and the tube was tilted to a $45^{\circ}$ angle on a filter paper, and then drained for $30 \mathrm{~min}$. Water-holding capacity was determined as the 
weight of the contents of the tube after draining divided by the weight of the dried EAP, and expressed as the weight $\%$ of dried EAP.

\subsubsection{Oil Holding Capacity (OHC)}

Oil holding capacity (OHC) was measured by the method of Lin et al. [50] with slight modifications. EAP $(0.5 \mathrm{~g})$ was placed in a centrifuge tube and weighed (tube with EAP). Soybean oil $(10 \mathrm{~mL})$ was added and the EAP/oil solution was then vortexed for 5 s every $15 \mathrm{~min}$, and up to $1 \mathrm{~h}$. Subsequently, the mixture was centrifuged at $5869 \times g$ for $20 \mathrm{~min}$ with the refrigerated centrifuge Rotina 380R. The upper phase was discarded and the centrifuge tube was tilted to a $45^{\circ}$ angle on a filter paper, and then drained for $30 \mathrm{~min}$. The EAP fat-binding capacity was determined as the weight of the tube content after draining divided by the weight of the dried EAP, and expressed as the weight $\%$ of dried EAP.

\subsubsection{Foaming Properties}

Foam capacity (FC) and foam stability (FS) of EAP were determined according to the method described by Ben Romdhane et al. [52]. Ten milliliters of EAP solution at different concentrations $(w / v)$ ranging from $0.5 \%$ to $5 \%$ were homogenized using a Moulinex R62 homogenizer (Organotechnie, La Courneuve, France) to incorporate air for $2 \mathrm{~min}$ at room temperature $\left(20 \pm 1^{\circ} \mathrm{C}\right)$. Whipped samples were then immediately transferred into a graduated cylinder to record the volume of foam formed after expansion. The foam volume remaining up to $60 \mathrm{~min}$ was measured.

Foam expansion, expressed as the percentage of volume increased immediately after homogenization, was calculated according to Equation (1).

$$
F C(\%)=\frac{V_{T}-V_{0}}{V_{0}} 100
$$

FS was measured as the volume of foam remaining after $10 \mathrm{~min}, 20 \mathrm{~min}, 30 \mathrm{~min}$, and $60 \mathrm{~min}$, compared with the initial volume before whipping. The $F S$ was determined according to Equation (2).

$$
F S(\%)=\frac{V_{T}-V_{0}}{V_{0}} 100
$$

where $V_{T}$ is the total volume after whipping $(\mathrm{mL}), V_{0}$ is the volume before whipping, and $V_{t}$ is the total volume after leaving at room temperature between $10 \mathrm{~min}$ and $60 \mathrm{~min}$.

\subsubsection{Emulsification Properties}

The emulsification properties of EAP were assessed according to the method described by Ben Romdhane et al. [23], with modifications. Different samples of $30 \mathrm{~mL}$ EAP suspensions at different concentrations $(0.5 \%, 1 \%, 2 \%, 3 \%, 4 \%$, and $5 \% ; w / v)$ were mixed with $10 \mathrm{~mL}$ soybean oil and homogenized for 3 min using a Moulinex R62 homogenizer. Aliquots of the emulsion $(50 \mu \mathrm{L})$ were taken from the bottom of the container immediately, and after $10 \mathrm{~min}$, and diluted with $5 \mathrm{~mL}$ of $0.1 \%$ sodium dodecyl sulfate (SDS) solution. Subsequently, the absorbance of the diluted emulsions was measured at $500 \mathrm{~nm}$ using a spectrophotometer UV-mini 1240 (Shimadzu, Beijing, China). Emulsion capacity (EC) was determined by reading the absorbance immediately after the formation of the emulsion. The emulsion activity index (EAI) was then evaluated according to Equation (3).

$$
\operatorname{EAI}\left(m^{2} \times g^{-1}\right)=\frac{2 \times 2.303 \times A_{0}}{\varphi \times E \text { APweight }(g)}
$$

where $A_{0}$ is the absorbance measured immediately after emulsion formation at $500 \mathrm{~nm}$, and $\Phi$ presents the oil volumetric fraction $(0.25)$. 
The emulsion stability (ES) was evaluated according to Equation (4).

$$
E S(\%)=\frac{A_{10}}{A_{0}} 100
$$

where $A_{0}$ and $A_{10}$ correspond to the initial absorbance and that measured after $10 \mathrm{~min}$, respectively.

\subsection{Antioxidant Activity of EAP}

\subsubsection{Determination of Total Antioxidant Capacity}

The total antioxidant activity (TAC) of the EAP was measured by the phosphate molybdate test according to the method described by Bouaziz et al. [53]. The assay is based on the reduction of Mo (VI) to Mo $(\mathrm{V})$ by the extract and subsequent formation of a green phosphate/Mo $(\mathrm{V})$ complex at acidic $\mathrm{pH}$. Samples $(100 \mu \mathrm{L})$ at various concentrations $(0.3,05,0.7,1,3,5,7$, and $10 \mathrm{mg} / \mathrm{mL})$ were mixed with $1 \mathrm{~mL}$ of reagent ( $0.6 \mathrm{M}$ sulfuric acid, $28 \mathrm{mM}$ sodium phosphate, and $4 \mathrm{mM}$ ammonium molybdate), and the mixtures were incubated at $95^{\circ} \mathrm{C}$ for $90 \mathrm{~min}$. After cooling to room temperature, the absorbance was measured at $695 \mathrm{~nm}$. BHA was used as a positive control, and the antioxidant activity was expressed as ascorbic acid equivalent using a standard curve.

\subsubsection{DPPH Radical-Scavenging Activity}

The DPPH• radical scavenging activity of EAP was assessed using the method described by Bouaziz et al. [54]. A volume of $500 \mu \mathrm{L}$ of each sample at different concentrations $(0.2,0.4,0.6,0.8$, and $1 \mathrm{mg} / \mathrm{mL}$ ) was mixed with $375 \mu \mathrm{L}$ of ethanol (99\%) and $125 \mu \mathrm{L}$ of DPPH solution $0.02 \%(w / v)$ prepared in ethanol. The mixture was stirred and then incubated in the absence of light at room temperature for $1 \mathrm{~h}$. The scavenging capacity was determined by monitoring the decrease of the absorbance at $517 \mathrm{~nm}$. The DPPH radical had a maximum absorbance at $517 \mathrm{~nm}$, which disappeared upon reduction by an antiradical compound. BHA was used as a positive control. The DPPH radical scavenging activity was calculated according to Equation (5).

$$
\text { DPPH radical scavenging activity }(\%)=\frac{A_{\text {control }}-A_{\text {sample }}}{A_{\text {control }}} 100
$$

where $A_{\text {control }}$ is the absorbance of the control reaction containing all the reagents except the sample, and $A_{\text {sample }}$ is the absorbance of the sample with the DPPH solution.

\subsubsection{ABTS Radical Scavenging Activity}

The ABTS radical scavenging activity of EAP was determined according to the method described by Bayar et al. [51], with modifications. The ABTS radical cation was the result of the reaction between aqueous solutions of ABTS (2,2'-azino-bis(3-ethylbenzothiazoline-6-sulfonic acid)) (7 mM) and potassium persulfate $(2.45 \mathrm{mM})$, after incubation for $12 \mathrm{~h}$ in obscurity at room temperature. The mixture was then diluted in ethanol to get an absorbance of $0.70 \pm 0.02$ at $734 \mathrm{~nm}$. For this test, different concentrations $(1-4 \mathrm{mg} / \mathrm{mL}$ ) of EAP solutions were used and $0.5 \mathrm{~mL}$ samples were mixed with $1 \mathrm{~mL}$ ABTS radical. After 6 min incubation at room temperature in obscurity, the absorbance of the mixture was measured at $734 \mathrm{~nm}$. Trolox was used as a positive control, and the ABTS radical scavenging activity was calculated with the same formula of the DPPH radical scavenging activity (Equation (5)).

\subsection{4. $\beta$-Carotene-Linoleic Acid Assay}

The ability of EAP to prevent bleaching of $\beta$-carotene was determined as described by Koubaa et al. [55]. A stock solution of $\beta$-carotene/linoleic acid mixture was prepared by dissolving $0.5 \mathrm{mg}$ of $\beta$-carotene, $25 \mu \mathrm{L}$ of linoleic acid, and $200 \mu \mathrm{L}$ of Tween 40 in $1 \mathrm{~mL}$ of chloroform. After evaporation of the chloroform under vacuum in a rotatory evaporator (Heidolph Instruments GmbH 
\& Co. KG, Schwabach, Germany) at $40{ }^{\circ} \mathrm{C}, 100 \mathrm{~mL}$ of bi-distilled water was added, and the resulting mixture was vigorously stirred. The emulsion obtained was freshly prepared before each experiment. Aliquots $(2.5 \mathrm{~mL})$ of the $\beta$-carotene/linoleic acid emulsion were transferred to test tubes containing $0.5 \mathrm{~mL}$ of each EAP at different concentrations $(1-5 \mathrm{mg} / \mathrm{mL})$. After incubation for $2 \mathrm{~h}$ at $50{ }^{\circ} \mathrm{C}$, the absorbance of each sample was measured at $470 \mathrm{~nm}$. BHA was used as a positive standard. A control consisting of $0.5 \mathrm{~mL}$ distilled water was used instead of the sample. The antioxidant activities of EAP were evaluated in terms of $\beta$-carotene bleaching according to Equation (6).

$$
A(\%)=\left(1-\frac{A_{0}-A_{2}}{A_{00}-A_{02}}\right) \times 100
$$

where $A_{0}$ and $A_{2}$ are the absorbance values measured in the presence of EAP at $\mathrm{t}=0$ and $\mathrm{t}=2 \mathrm{~h}$, respectively. $A_{00}$ and $A_{02}$ are the absorbance values measured in the absence of EAP at $\mathrm{t}=0$ and $\mathrm{t}=2$ $\mathrm{h}$, respectively.

\subsubsection{Reducing Power Assay}

The EAP ability to reduce iron (III) was evaluated as described by Ben Romdhane et al. [52]. A sample aliquot of $0.5 \mathrm{~mL}$ EAP at various concentrations $(1-5 \mathrm{mg} / \mathrm{mL})$ was mixed with $1 \mathrm{~mL}$ of $0.2 \mathrm{M}$ phosphate buffer $(\mathrm{pH} 6.6)$ and $1 \mathrm{~mL}$ of $1 \%(w / v) \mathrm{K}_{3} \mathrm{Fe}(\mathrm{CN})_{6}$ solution. After incubation at $50{ }^{\circ} \mathrm{C}$ for $20 \mathrm{~min}$, the reaction was stopped by adding $1 \mathrm{~mL}$ of $10 \%(w / v)$ trichloroacetic acid (TCA) solution, and the mixture was centrifuged for $10 \mathrm{~min}$ at $2113 \times \mathrm{g}$. An aliquot $(1.5 \mathrm{~mL})$ from the upper phase was diluted with $1.5 \mathrm{~mL}$ of distilled water and $0.1 \mathrm{~mL}$ of $0.1 \%(w / v) \mathrm{FeCl}_{3}$ solution. The absorbance values of the samples and ascorbic acid, used as a reference molecule, were measured at $700 \mathrm{~nm}$ using the UV-mini 1240 spectrophotometer after incubation for $10 \mathrm{~min}$. The higher absorbance of the reaction mixture indicated a greater reducing power. A control tube was conducted in the same conditions, where distilled water was used instead of the sample.

\subsubsection{Ferrous Ion-Chelating Activity}

The chelating antioxidant activity of EAP toward ferrous ions $\left(\mathrm{Fe}^{2+}\right)$ was measured according to the method described by Carter [56]. The chelating ability was monitored by measuring the decrease in the red color complex ( $\mathrm{Fe}^{2+}$-ferrozine) at $562 \mathrm{~nm}$. EDTA was used as a standard antioxidant compound. The inhibition percentage of ferrozine- $\mathrm{Fe}^{2+}$ complex formation was calculated according to Equation (7).

$$
\text { Ferrous ion - chelating activity }(\%)=\frac{A_{\text {control }}+A_{\text {blank }}-A_{\text {sample }}}{A_{\text {control }}} 100
$$

where $A_{\text {control }}$ is the absorbance of the control (without EAP), $A_{\text {blank }}$ is the absorbance of the EAP (without ferrozine), and $A_{\text {sample }}$ is the absorbance of the reaction tubes (using EAP with the ferrozine as a mixture).

\subsection{Determination of the ACE Inhibitory Activity of EAP}

The ACE inhibitory activity was measured as described by Nakamura et al. [57]. A sample solution containing different concentrations $(1-5 \mathrm{mg} / \mathrm{mL})$ of EAP $(80 \mu \mathrm{L})$ was mixed with $200 \mu \mathrm{L}$ of $5 \mathrm{mM}$ hippuryl-L-histidyl-L-leucine (HHL), and then pre-incubated for $3 \mathrm{~min}$ at $37^{\circ} \mathrm{C}$. EAP was prepared in $100 \mathrm{mM}$ borate buffer ( $\mathrm{pH} 8.3$ ), containing $300 \mathrm{mM} \mathrm{NaCl}$. The reactions were then initiated by adding $20 \mu \mathrm{L}$ of $0.1 \mathrm{U} / \mathrm{mL}$ ACE from rabbit lung prepared in the same buffer. After incubation for $30 \mathrm{~min}$ at $37^{\circ} \mathrm{C}$, the enzyme reactions were stopped by adding $250 \mathrm{~mL}$ of $0.05 \mathrm{M} \mathrm{HCl}$. The liberated hippuric acid (HA) was extracted with ethyl acetate $(1.7 \mathrm{~mL})$ and then evaporated at $90^{\circ} \mathrm{C}$ for $10 \mathrm{~min}$. The residue was dissolved in $1 \mathrm{~mL}$ of distilled water and the absorbance of the extract was measured at $228 \mathrm{~nm}$. The ACE inhibition percentage was calculated according to Equation (8). 


$$
\text { ACE inhibition }(\%)=\frac{B-A}{B-C} 100
$$

where $A$ is the absorbance of HA obtained in the presence of ACE inhibitor, $B$ is the absorbance of HA without ACE inhibitors (100 mM borate buffer $\mathrm{pH} 8.3$ was used instead of EAP), and $\mathrm{C}$ is the absorbance of HA without ACE (corresponding to HHL autolysis in the course of the enzymatic assay). The $\mathrm{IC}_{50}$ value, defined as the concentration of EAP $(\mathrm{mg} / \mathrm{mL})$ required to inhibit $50 \%$ of ACE activity, was calculated for each sample using non-linear regression from a plot of ACE inhibition percentage versus sample concentrations.

\subsection{Statistical Analyses}

All experiments were conducted in triplicate and the average values with standard deviation errors were reported.

\section{Conclusions}

In this work, water-soluble polysaccharides (EAP) were extracted from E. alata stems and characterized to investigate their functional properties, as well as their antioxidant and antihypertensive activities. The monosaccharide composition of EAP showed that glucose was the most abundant sugar $(43.1 \%)$, followed by galactose (36.4\%), mannose $(14.9 \%)$, arabinose $(3.7 \%)$, and gluconic acid $(1.7 \%)$. EAP showed interesting water-holding capacity, fat-binding ability, foaming and emulsion properties, antioxidant activity, and potential ACE inhibition activity. These results proved that the EAP could be incorporated into different food formulations to improve their biological and functional properties. Nevertheless, deeper analyses should be performed on EAP to confirm the activities found in this work in vivo, as well as evaluate the cytotoxicity of EAP and the feasible scalability of the proposed process.

Author Contributions: Conceptualization, S.E.C.; methodology, L.S. and J.F.; formal analysis, H.K.G.; investigation, L.S.; resources, S.E.C.; writing-original draft preparation, L.S. and M.K.; writing-review and editing, L.S., M.K., and F.J.B.; supervision, S.E.C.; funding acquisition, S.E.C. All authors have read and agreed to the published version of the manuscript.

Funding: This research was funded by the Ministry of Higher Education and Scientific Research in Tunisia.

Acknowledgments: The authors thank Ferjani Ben Abdallah, a botanical taxonomist from Faculty of Sciences, University of Sfax (Tunisia), for the taxonomic identification of Ephedra alata plant, and Hanen Mallek-Fakhfakh for the precious help and advice. Finally, we thank Pr. Kamel MAALOUL, interpreter and English professor, for proofreading the manuscript.

Conflicts of Interest: The authors declare no conflict of interest.

\section{References}

1. Jia, X.; Dong, L.; Yang, Y.; Yuan, S.; Zhang, Z.; Yuan, M. Preliminary structural characterization and antioxidant activities of polysaccharides extracted from Hawk tea (Litsea coreana var. lanuginosa). Carbohydr. Polym. 2013, 95, 195-199. [CrossRef] [PubMed]

2. Shi, J.-J.; Zhang, J.-G.; Sun, Y.-H.; Qu, J.; Li, L.; Prasad, C.; Wei, Z.-J. Physicochemical properties and antioxidant activities of polysaccharides sequentially extracted from peony seed dreg. Int. J. Biol. Macromol. 2016, 91, 23-30. [CrossRef] [PubMed]

3. Ktari, N.; Feki, A.; Trabelsi, I.; Triki, M.; Maalej, H.; Slima, S.B.; Nasri, M.; Ben Amara, I.; Ben Salah, R. Structure, functional and antioxidant properties in Tunisian beef sausage of a novel polysaccharide from Trigonella foenum-graecum seeds. Int. J. Biol. Macromol. 2017, 98, 169-181. [CrossRef] [PubMed]

4. Jin, M.; Zhao, K.; Huang, Q.; Shang, P. Structural features and biological activities of the polysaccharides from Astragalus membranaceus. Int. J. Biol. Macromol. 2014, 64, 257-266. [CrossRef] [PubMed]

5. Bouaziz, F.; Koubaa, M.; Helbert, C.B.; Kallel, F.; Driss, D.; Kacem, I.; Ghorbel, R.; Chaabouni, S.E. Purification, structural data and biological properties of polysaccharide from Prunus amygdalus gum. Int. J. Food Sci. Technol. 2015, 50, 578-584. [CrossRef] 
6. Fimbres-Olivarria, D.; Carvajal-Millan, E.; Lopez-Elias, J.A.; Martinez-Robinson, K.G.; Miranda-Baeza, A.; Martinez-Cordova, L.R.; Enriquez-Ocaña, F.; Valdez-Holguin, J.E. Chemical characterization and antioxidant activity of sulfated polysaccharides from Navicula sp. Food Hydrocoll. 2018, 75, 229-236. [CrossRef]

7. Funami, T.; Nakauma, M.; Ishihara, S.; Tanaka, R.; Inoue, T.; Phillips, G.O. Structural modifications of sugar beet pectin and the relationship of structure to functionality. Food Hydrocoll. 2011, 25, 221-229. [CrossRef]

8. Ziani, B.E.C.; Heleno, S.A.; Bachari, K.; Dias, M.I.; Alves, M.J.; Barros, L.; Ferreira, I.C.F.R. Phenolic compounds characterization by LC-DAD- ESI/MSn and bioactive properties of Thymus algeriensis Boiss. \& Reut. and Ephedra alata Decne. Food Res. Int. 2019, 116, 312-319.

9. Al-Qarawi, A.; Abd Allah, A.A.; Hashem, A. Effect of Ephedra alata on nucleic acids and nitrogen metabolism of seedborne Aspergillus flavus. Pak. J. Bot. 2012, 44, 425-428.

10. Jaradat, N.; Hussen, F.; Al Ali, A. Preliminary phytochemical screening, quantitative estimation of total flavonoids, total phenols and antioxidant activity of Ephedra. J. Mater. Environ. Sci. 2015, 6, 1771-1778.

11. Liang, S.; Meng, X.; Wang, Z.; Liu, J.; Kuang, H.; Wang, Q. Polysaccharide from Ephedra sinica Stapf inhibits inflammation expression by regulating Factor- $\beta 1 /$ Smad2 signaling. Int. J. Biol. Macromol. 2018, 106, 947-954. [CrossRef] [PubMed]

12. Wang, Q.; Shu, Z.; Xing, N.; Xu, B.; Wang, C.; Sun, G.; Sun, X.; Kuang, H. A pure polysaccharide from Ephedra sinica treating on arthritis and inhibiting cytokines expression. Int. J. Biol. Macromol. 2016, 86, 177-188. [CrossRef] [PubMed]

13. Kim, I.-S.; Park, Y.-J.; Yoon, S.-J.; Lee, H.-B. Ephedrannin A and B from roots of Ephedra sinica inhibit lipopolysaccharide-induced inflammatory mediators by suppressing nuclear factor- $\mathrm{kB}$ activation in RAW 264.7 macrophages. Int. Immunopharmacol. 2010, 10, 1616-1625. [CrossRef] [PubMed]

14. Bagheri-Gavkosh, S.; Bigdeli, M.; Shams-Ghahfarokhi, M.; Razzaghi-Abyaneh, M. Inhibitory effects of Ephedra major Host on Aspergillus parasiticus growth and aflatoxin production. Mycopathologia 2009, 168, 249-255. [CrossRef] [PubMed]

15. Li, G.-H.; Le, G.-W.; Shi, Y.-H.; Shrestha, S. Angiotensin I-converting enzyme inhibitory peptides derived from food proteins and their physiological and pharmacological effects. Nutr. Res. 2004, 24, 469-486. [CrossRef]

16. Chen, Y.; Liu, W.; Xue, J.; Yang, J.; Chen, X.; Shao, Y.; Kwok, L.; Bilige, M.; Mang, L.; Zhang, H. Angiotensin-converting enzyme inhibitory activity of Lactobacillus helveticus strains from traditional fermented dairy foods and antihypertensive effect of fermented milk of strain H9. J. Dairy Sci. 2014, 97, 6680-6692. [CrossRef]

17. Schiffrin, E.L.; Touyz, R.M. From bedside to bench to bedside: Role of renin-angiotensin-aldosterone system in remodeling of resistance arteries in hypertension. Am. J. Physiol. Heart Circ. Physiol. 2004, 287, H435-H446. [CrossRef]

18. De Cavanagh, E.M.; Inserra, F.; Ferder, L.; Fraga, C.G. Enalapril and captopril enhance glutathione-dependent antioxidant defenses in mouse tissues. Am. J. Physiol. Regul. Integr. Comp. Physiol. 2000, 278, R572-R577. [CrossRef]

19. Jayasinghe, C.; Gotoh, N.; Wada, S. Pro-oxidant/antioxidant behaviours of ascorbic acid, tocopherol, and plant extracts in n-3 highly unsaturated fatty acid rich oil-in-water emulsions. Food Chem. 2013, 141, 3077-3084. [CrossRef]

20. Athmouni, K.; Belhaj, D.; El Feki, A.; Ayadi, H. Optimization, antioxidant potential, modulatory effect and anti-apoptotic action in of Euphorbia bivonae polysaccharides on hydrogen peroxide-induced toxicity in human embryonic kidney cells HEK293. Int. J. Biol. Macromol. 2018, 116, 482-491. [CrossRef]

21. Kuang, H.; Xia, Y.; Yang, B.; Wang, Q.; Wang, Y. Screening and comparison of the immunosuppressive activities of polysaccharides from the stems of Ephedra sinica Stapf. Carbohydr. Polym. 2011, 83, 787-795. [CrossRef]

22. Xia, Y.; Kuang, H.; Yang, B.; Wang, Q.; Liang, J.; Sun, Y.; Wang, Y. Optimum extraction of acidic polysaccharides from the stems of Ephedra sinica Stapf by Box-Behnken statistical design and its anti-complement activity. Carbohydr. Polym. 2011, 84, 282-291. [CrossRef]

23. Kravchenko, A.O.; Byankina Barabanova, A.O.; Glazunov, V.P.; Yakovleva, I.M.; Yermak, I.M. Seasonal variations in a polysaccharide composition of Far Eastern red seaweed Ahnfeltiopsis flabelliformis (Phyllophoraceae). J. Appl. Phycol. 2018, 30, 535-545. [CrossRef] 
24. Ben Slima, S.; Ktari, N.; Trabelsi, I.; Moussa, H.; Makni, I.; Ben Salah, R. Purification, characterization and antioxidant properties of a novel polysaccharide extracted from Sorghum bicolor (L.) seeds in sausage. Int. J. Biol. Macromol. 2018, 106, 168-178. [CrossRef] [PubMed]

25. Hu, Z.; Wang, P.; Zhou, H.; Li, Y. Extraction, characterization and in vitro antioxidant activity of polysaccharides from Carex meyeriana Kunth using different methods. Int. J. Biol. Macromol. 2018, 120, 2155-2164. [CrossRef]

26. Jayasinghe, P.; Pahalawattaarachchi, V.; Ranaweera, K. Effect of extraction methods on the yield and physiochemical properties of polysaccharides extracted from seaweed available in Sri Lanka. Poult. Fish. Wildl. Sci. 2016, 4, 1-6. [CrossRef]

27. Ben Jeddou, K.; Chaari, F.; Maktouf, S.; Nouri-Ellouz, O.; Boisset Helbert, C.; Ellouz Ghorbel, R. Structural, functional, and antioxidant properties of water-soluble polysaccharides from potatoes peels. Food Chem. 2016, 205, 97-105. [CrossRef]

28. Wu, C.-S. Renewable resource-based composites of recycled natural fibers and maleated polylactide bioplastic: Characterization and biodegradability. Polym. Degrad. Stab. 2009, 94, 1076-1084. [CrossRef]

29. Zhu, J.; Liu, W.; Yu, J.; Zou, S.; Wang, J.; Yao, W.; Gao, X. Characterization and hypoglycemic effect of a polysaccharide extracted from the fruit of Lycium barbarum L. Carbohydr. Polym. 2013, 98, 8-16. [CrossRef]

30. Liu, Z.; Dang, J.; Wang, Q.; Yu, M.; Jiang, L.; Mei, L.; Shao, Y.; Tao, Y. Optimization of polysaccharides from Lycium ruthenicum fruit using RSM and its anti-oxidant activity. Int. J. Biol. Macromol. 2013, 61, 127-134. [CrossRef]

31. Parker, F. Applications of Infrared Spectroscopy in Biochemistry, Biology, and Medicine; Springer Science \& Business Business Media, Plenum: New York, NY, USA, 1971.

32. Cheng, H.; Feng, S.; Jia, X.; Li, Q.; Zhou, Y.; Ding, C. Structural characterization and antioxidant activities of polysaccharides extracted from Epimedium acuminatum. Carbohydr. Polym. 2013, 92, 63-68. [CrossRef] [PubMed]

33. Gannasin, S.P.; Adzahan, N.M.; Hamzah, M.Y.; Mustafa, S.; Muhammad, K. Physicochemical properties of tamarillo (Solanum betaceum Cav.) hydrocolloid fractions. Food Chem. 2015, 182, 292-301. [CrossRef] [PubMed]

34. Biswas, A.K.; Kumar, V.; Bhosle, S.; Sahoo, J.; Chatli, M.K. Dietary fibre as functional ingredients in meat products and their role in human health. Int. J. Livest. Prod. 2010, 2, 45-54.

35. Dickinson, E. Hydrocolloids at interfaces and the influence on the properties of dispersed systems. Food Hydrocoll. 2003, 17, 25-39. [CrossRef]

36. Mokni Ghribi, A.; Sila, A.; Maklouf Gafsi, I.; Blecker, C.; Danthine, S.; Attia, H.; Bougatef, A.; Besbes, S. Structural, functional, and ACE inhibitory properties of water-soluble polysaccharides from chickpea flours. Int. J. Biol. Macromol. 2015, 75, 276-282. [CrossRef]

37. Benhura, M.A.N.; Chidewe, C.K. The emulsifying properties of a polysaccharide isolated from the fruit of Cordia abyssinica. Int. J. Food Sci. Technol. 2004, 39, 579-583. [CrossRef]

38. Saleh, M.A.; Clark, S.; Woodard, B.; Deolu-Sobogun, S.A. Antioxidant and free radical scavenging activities of essential oils. Ethn. Dis. 2010, 20, S78-S82.

39. Chen, R.; Jin, C.; Li, H.; Liu, Z.; Lu, J.; Li, S.; Yang, S. Ultrahigh pressure extraction of polysaccharides from Cordyceps militaris and evaluation of antioxidant activity. Sep. Purif. Technol. 2014, 134, 90-99. [CrossRef]

40. Cheng, Z.; Zhang, Y.; Song, H.; Zhou, H.; Zhong, F.; Hu, H.; Feng, Y. Extraction optimization, characterization and antioxidant activity of polysaccharide from Gentiana scabra bge. Int. J. Biol. Macromol. 2016, 93, 369-380. [CrossRef]

41. Sila, A.; Bayar, N.; Ghazala, I.; Bougatef, A.; Ellouz-Ghorbel, R.; Ellouz-Chaabouni, S. Water-soluble polysaccharides from agro-industrial by-products: Functional and biological properties. Int. J. Biol. Macromol. 2014, 69, 236-243. [CrossRef]

42. Hammami, N.; Gara, A.B.; Bargougui, K.; Ayedi, H.; Abdalleh, F.B.; Belghith, K. Improved in vitro antioxidant and antimicrobial capacities of polysaccharides isolated from Salicornia arabica. Int. J. Biol. Macromol. 2018, 120, 2123-2130. [CrossRef] [PubMed]

43. Sellimi, S.; Maalej, H.; Rekik, D.M.; Benslima, A.; Ksouda, G.; Hamdi, M.; Sahnoun, Z.; Li, S.; Nasri, M.; Hajji, M. Antioxidant, antibacterial and in vivo wound healing properties of laminaran purified from Cystoseira barbata seaweed. Int. J. Biol. Macromol. 2018, 119, 633-644. [CrossRef] 
44. Song, H.; Zhang, Q.; Zhang, Z.; Wang, J. In vitro antioxidant activity of polysaccharides extracted from Bryopsis plumosa. Carbohydr. Polym. 2010, 80, 1057-1061. [CrossRef]

45. Tan, H.-F.; Gan, C.-Y. Polysaccharide with antioxidant, $\alpha$-amylase inhibitory and ACE inhibitory activities from Momordica charantia. Int. J. Biol. Macromol. 2016, 85, 487-496. [CrossRef] [PubMed]

46. Ding, X.; Hou, Y.; Hou, W. Structure feature and antitumor activity of a novel polysaccharide isolated from Lactarius deliciosus Gray. Carbohydr. Polym. 2012, 89, 397-402. [CrossRef] [PubMed]

47. Dubois, M.; Gilles, K.A.; Hamilton, J.K.; Rebers, P.A.; Smith, F. Colorimetric method for determination of sugars and related substances. Anal. Chem. 1956, 28, 350-356. [CrossRef]

48. Bitter, T.; Muir, H.M. A modified uronic acid carbazole reaction. Anal. Biochem. 1962, 4, 330-334. [CrossRef]

49. Horwitz, W. Official Methods of Analysis of AOAC International, 17th ed.; AOAC International: Gaithersburg, MD, USA, 2000.

50. He, R.; Zhao, Y.; Zhao, R.; Sun, P. Antioxidant and antitumor activities in vitro of polysaccharides from E. sipunculoides. Int. J. Biol. Macromol. 2015, 78, 56-61. [CrossRef]

51. Bayar, N.; Kriaa, M.; Kammoun, R. Extraction and characterization of three polysaccharides extracted from Opuntia ficus indica cladodes. Int. J. Biol. Macromol. 2016, 92, 441-450. [CrossRef]

52. Ben Romdhane, M.; Haddar, A.; Ghazala, I.; Ben Jeddou, K.; Helbert, C.B.; Ellouz-Chaabouni, S. Optimization of polysaccharides extraction from watermelon rinds: Structure, functional and biological activities. Food Chem. 2017, 216, 355-364. [CrossRef]

53. Bouaziz, F.; Boisset Helbert, C.; Ben Romdhane, M.; Koubaa, M.; Bhiri, F.; Kallel, F.; Chaari, F.; Driss, D.; Buon, L.; Ellouz Chaabouni, S. Structural data and biological properties of almond gum oligosaccharide: Application to beef meat preservation. Int. J. Biol. Macromol. 2015, 72, 472-479. [CrossRef] [PubMed]

54. Bouaziz, F.; Koubaa, M.; Barba, F.J.; Roohinejad, S.; Chaabouni, S.E. Antioxidant properties of water-soluble gum from flaxseed hulls. Antioxidants 2016, 5, 26. [CrossRef] [PubMed]

55. Koubaa, M.; Driss, D.; Bouaziz, F.; Ellouz Ghorbel, R.; Ellouz Chaabouni, S. Antioxidant and antimicrobial activities of solvent extract obtained from rocket (Eruca sativa L.) flowers. Free Radic. Antioxid. 2015, 5, $29-34$. [CrossRef]

56. Carter, P. Spectrophotometric determination of serum iron at the submicrogram level with a new reagent (ferrozine). Anal. Biochem. 1971, 40, 450-458. [CrossRef]

57. Nakamura, Y.; Yamamoto, N.; Sakai, K.; Okubo, A.; Yamazaki, S.; Takano, T. Purification and characterization of angiotensin I-converting enzyme inhibitors from sour milk. J. Dairy Sci. 1995, 78, 777-783. [CrossRef]

Sample Availability: Not available.

(C) 2020 by the authors. Licensee MDPI, Basel, Switzerland. This article is an open access article distributed under the terms and conditions of the Creative Commons Attribution (CC BY) license (http://creativecommons.org/licenses/by/4.0/). 